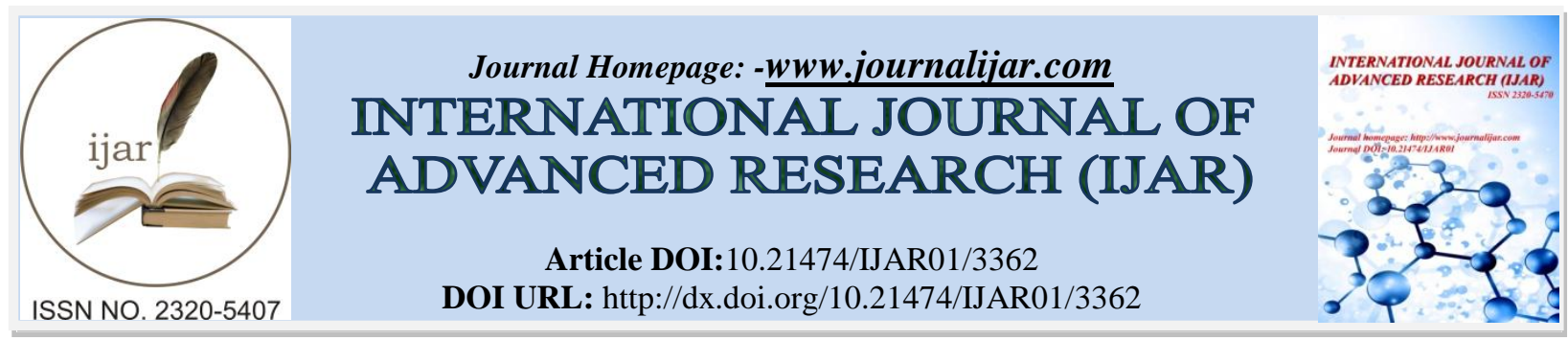

RESEARCH ARTICLE

\title{
OPTIMIZATION OF BUS BODY BUILDING METHODS BY INVESTIGATION OF THE EXISTING PROBLEMS AND RECTIFICATION IN ADDIS ABABA, ETHIOPIA.
}

Teshome Dengiso Megiso.

Arba Minch University Institute of Technology, Department of Mechanical Engineering.

\section{Manuscript Info}

Manuscript History

Received: 29 December 2016

Final Accepted: 15 January 2017

Published: February 2017

Key words:-

Bus body building, heavier bus bodies, spurious materials, and non-uniform construction.

\section{Abstract}

The design of the bus body depends largely upon the performance requirements under various types of loading, operating and the road conditions.Nowadays for the passenger buses there are many local producers which construct vehicles based on local needs. The big challenges found in the bus body building companies are applying spurious materials, heavier bus bodies;non-uniform construction and absence of code of practice for bus body design and approval.In the competitive to stay these producers comply with the same requirements of their international counterparts without access to latest computation facilities. This paper explores the existing problems in the industry and proposes the right solution to optimize the bus body manufacturing. To achieve the expected research goals, the researcher randomly selected one hundred fifty locally manufactured buses. The tools used are; statistical analysis, Pareto chart/diagram, cause and effect analysis, field observation and literature survey.

Copy Right, IJAR, 2017,. All rights reserved.

\section{Introduction:-}

Automobile Body Building in Ethiopia:-

Ethiopia imports automobiles, buses/coaches, trucks, equipment's/machineries and spare parts from abroad. It does not manufacture automotive products. Some companies only assemble and build bodies of buses and dry and wet cargo on chassis imported with cab. The automotive industry is serving the transportation of freight and passenger. This studyis concerned with the investigation of the major problems and challenges existing in passenger bus body building sector.

The bus body building industry will have huge contribution to the growth of the national economy if it is well addressed and supported with attractive incentives.

The major areas the contribution can be felt easily along:

- Job creation

- Saving foreign currency

- Technology transfer and progress

The major problems observed in the local bus body building sector are absence of national standard, lack of adequate testing tools/ machines, shortage of skilled manpower and shortage of advanced machines to manufacture 
different internal and external structures to be manufactured from different materials (metallic and nonmetallic) and limitation of some advanced lightest materials like composites and plastics.

During service, any vehicle is subjected to loads that cause stresses, vibrations and noise in the different components of its structure. This requires appropriate strength, stiffness and fatigue properties of the components to be able to stand these loads. On top of that, quality of a vehicle, as a system, which include efficient energy consumption, safety, and provision of comfort to the user are highly desired.

Companies construct bus body on most popularly used Isuzu models like NPR, NQR and FSR series for commercial intercity passenger transportation purposes. Local bus body manufacturers started body building by making 'wuyiyit', a locally manufactured taxi body structure, on Toyota, Nissan, and Peugeot model pick up vehicles.

It was noticed that the vehicle manufacturers sell their products in the form of drive away chassis and the body design and building is being done by way side body builders who employ poor design, poor quality products, spurious materials and parts, with no uniformity in the construction, resulting in large amounts of fatal accidents, reduced product life, reduced vehicle performance, poor safety and comfort for the passengers. The cabins and seats have cramped designs which do not provide safety and comfort to the driver. Body designs offer extreme heat, vibration, noise, poor comfort and protection. Wood is being used in the construction of the body to a large extent. Of late some reputed body builders have brought in improved bus designs in the market but still a lot has to be done.

Hence the paper addresses on selected areas to investigate the major challenges in the bus body manufacturing companies and suggests scientific ways to optimize the process.

\section{Planning of Bodies, selecting chassis and Vehicle Modifications:-}

When designing vehicle bodies in addition to a user-friendly and maintenance friendly design, the careful choice of materials and, in consequence, the associated corrosion protection measures and of great importance.

In order to ensure safe operation of the vehicle, it is essential to choose the chassis carefully in accordance with the intended use. Planning should therefore consider the following items in particular and adapt them to the intended use wheelbase, engine, axle, maximum permissible gross vehicle weight and position of the center of gravity [1].

Before carrying out any work on the body or modification work, the delivered vehicle must be submitted to a check to verify whether it fulfills the necessary requirements.

Before starting work, the body builder must check whether:

* The vehicle is suitable for the planned body

* The chassis model and equipment are suitable for the operating conditions intended for the body.

\section{Purpose and Requirements of Vehicle Body Structures:-}

The purpose of the bus body structure is to maintain the shape of the vehicle and to support the various loads applied to it and to carry the passengers and/or payload in a safe and comfortable manner. The structure usually accounts for a large proportion of the development and manufacturing cost in a new vehicle programme, and many different structural concepts are available to the designer. It is essential that the best one is chosen to ensure acceptable structural performance within other design constraints such as cost, volume and method of production, product application [1].

The structural requirements of any vehicle structure can be summarized as follows:

a. The structure must be sufficiently stiff to withstand the static loads and dynamic loads without excessive deformation

b. The structure must be sufficiently strong to withstand many cycles of the applied loading without suffering from fatigue or other forms of material failure

c. The structure should deform in such a manner under impact load conditions so as the minimize the risk of injury to the occupants and other road users

Assessments of the performance of a vehicle structure are related to its strength and stiffness. A design aim is to achieve sufficient levels of these with as little mass as possible [2]. 
In the event of collision, the body must be capable of transforming as much kinetic energy as possible into deformation work while minimizing deformation of the vehicle interior [3].

Sheet steel of various grades is customarily used for the vehicle body structure. Sheet thickness from 0.6 to $3 \mathrm{~mm}$ with most pieces being between 0.8 and $1.0 \mathrm{~mm}$ thick. Due to the mechanical properties of steel with regard to stiffness, strength, economy and ductility, alternative materials for the vehicle body structure are not yet available. High strength, low alloy (HSLA) sheet steel is used for highly stressed structural components. The increased strength of these components allows their thickness to be reduced.

The light weight construction a priority-Low weight construction of vehicles is a top priority at DaimlerChrysler. Besides aluminum, magnesium, ceramics and carbon-reinforced plastics extremely light materials now include high strength steels, said Pollman. Components made of these new high- tech materials are up to $60 \%$ lighter than those made of conventional steel, the use of which will decline substantially.

Developing the materials and production technologies that open up these materials for the design of motor vehicles is one of the most important core technologies at DaimlerChrysler. Low weight materials can increase performance, quality and driving pleasure. Moreover, they can improve environmental soundness while reducing costs. Know-how regarding materials and production technologies is a key competitive factor [2] [4].

The strength requirements which must be met by the seats in a collision pertain to the seat cushion and backrest, the head restraints, the seat adjustment mechanism and the seat anchors(pertinent regulations: FMVSS 207,202; ECE-R 17,25;RREG 74/408,78/932 and others). One component of active safety is seating comfort. Seats must be designed such that vehicle occupants with different body dimensions do not suffer from driving fatigue.

Strength analysis for individual parts and body areas which are subject to specific stresses caused by factors such as restraints systems or trailer loads, detailed examinations are carried out with the aim of providing proof of sufficient strength or of reducing unacceptable stresses by modifying the design[5].

\section{Modern Advanced Lightweight Materials, Weight and Vehicle Performance:-}

Reducing the loads (weight, rolling and air resistance and accessory loads) on the vehicle, thus reducing the work needed to operate it; The loads on the vehicle consist of the force needed to accelerate the vehicle, to overcome inertia; vehicle weight when climbing slopes; the rolling resistance of the tires; aerodynamic forces; and accessory loads. In urban stop-and-go driving, aerodynamic forces play little role, but rolling resistance and especially inertial forces are critical. In steady highway driving, aerodynamic forces dominate, because these forces increase with the square of velocity; aerodynamic forces at $90 \mathrm{~km} / \mathrm{h} 10$ re four times the forces at $45 \mathrm{~km} / \mathrm{h}$. Reducing inertial loads is accomplished by reducing vehicle weight, with improved design and greater use of lightweight materials[6].

A $10 \%$ weight reduction from a total vehicle weight can improve fuel economy by 4-8\%, expending on changes in vehicle size and whether or not the engine is downsized. There are several ways to reduce vehicle weight; including switching to high strength steels (HSS), replacing steel by lighter materials such as $\mathrm{Al}, \mathrm{Mg}$ and plastics, evolution of lighter design concepts and forming technologies. The amount of lighter materials in vehicles has been progressively increasing over time, although not always resulting in weight reductions and better fuel economy if they are used to increase the size or performance of the vehicle. In fact, the average weight of a vehicle in the USA and Japan has increased by $10-20 \%$ in the last 10 years (JAMA, 2002; Haight, 2003), partly due to increased concern for safety and customers' desire for greater comfort [7].

Steel is still the main material used in vehicles, currently averaging $70 \%$ of curb weight. Aluminum usage has grown to roughly $100 \mathrm{~kg}$ per average passenger car, mainly in the engine, drive train and chassis in the form of castings and forgings. Aluminum is twice as strong as an equal weight of steel, allowing the designer to provide strong, yet lightweight structures. Aluminum use in body structures is limited, but there are a few commercial vehicles with all Al bodies (e.g., Audi's A2 and A8). Where more than $200 \mathrm{~kg}$ of Al is used and secondary weight reductions are gained by down-sizing the engine and suspension - more than 11-13\% weight reduction can be achieved. Ford's P2000 concept car11 has demonstrated that up to $300 \mathrm{~kg}$ of Al can be used in a $900 \mathrm{~kg}$ vehicle.

The use of plastics in vehicles has increased to about $8 \%$ of total vehicle weight, which corresponds to $100-120 \mathrm{~kg}$ per vehicle. The growth rate of plastics content has been decreasing in recent years however, probably due to 
concerns about recycling, given that most of the plastic goes to the automobile shredder residue (ASR) at the end of vehicle life. Fiber reinforced plastic (FRP) is now widely used in aviation, but its application to automobiles is limited due to its high cost and long processing time. However, its weight reduction potential is very high, maybe as much as $60 \%$. Examples of FRP structures manufactured using RTM (resin transfer method) technology are wheel housings or entire floor assemblies. For a compact size car, this would make it possible to reduce the weight; of a floor assembly (including wheel housings) by $60 \%$, or $22 \mathrm{~kg}$ per car compared to a steel floor assembly. Research examples of plastics use in the chassis are leaf or coil springs manufactured from fiber composite plastic. Weight reduction potentials of up to $63 \%$ have been achieved in demonstrators using glass and/or carbon fiber structures (Friedricht, 2002).

Aside from the effect of the growing use of non-steel materials, the reduction in the average weight of steel in a car is driven by the growing shift from conventional steels to high strength steels (HSS). There are various types of HSS, from relatively low strength grade (around $400 \mathrm{MPa}$ ) such as solution-hardened and precipitation-hardened HSS to very high strength grade (980-1400 MPa) such as TRIP steel and tempered martensitic HSS. At present, the average usage per vehicle of HSS is $160 \mathrm{~kg}$ (11\% of whole weight) in the USA 11 and $75 \mathrm{~kg}$ (7\%) in Japan. In the latest Mercedes A-class vehicle, HSS comprises $67 \%$ of body structure weight. The international ULSAB-AVC project (Ultra-Light Steel Auto Body - Advanced Vehicle Concept) investigated intensive use of HSS, including advanced HSS, and demonstrated that using HSS as much as possible can reduce vehicle weight by $214 \mathrm{~kg}(-19 \%)$ and $472 \mathrm{~kg}(-32 \%)$ for small and medium passenger cars respectively. In this concept, the total usage of HSS in body and closures structures is $280-330 \mathrm{~kg}$, of which over $80 \%$ is advanced HSS (Nippon Steel, 2002).

\section{Methods and Materials:-}

Different options available to carry out the study and gives reasons why a particular method was selected at different stages of the project. The research is intended to answer the following questions;

* What are the main methods which can be implemented to reduce the weight of the buses during body modification?

* Are there any proper rules and regulations (national standard code of practice for bus body building, design and approval) set by the respective bodies to control the process.

* What measures should be taken to improve the bus interior structure to make the bus comfortable and safe for occupants.

To address these research questions, the following steps are carried out during different phase of the study:

Statistical analysis of the data collected from the Transport Authority.

* Literature survey

* Close observation of the procedures practiced in the bus body building units.

* Pareto chart analysis to pin point the potential causing factor.

* Cause and effect analysis of the problem.

* Recognize how different groups benefit from the study

\section{Research Method:-}

The method used when collecting, processing and analyzing the gathered information can be either quantitative or qualitative research method.

The nature of the present study requires both quantitative and qualitative information to obtain best results and to propose important recommendation. Both kinds of methods have also been used to support conclusions made in this thesis. Mixing qualitative and quantitative research methods is called triangulation method. While most researchers develop expertise in one style, the two types of methods have different, complementary strengths and when used together can lead to a more comprehensive understanding of a phenomenon.

\section{Data Collection Techniques:-}

Depending on the research perspective and strategy chosen, the researcher must choose methods for collecting data. The data or information collected by the researcher can be either primary, i.e. the researcher collects the material himself, or secondary, i.e. already documented material are being used as a data source, which can be done in either quantitative or qualitative way. In this thesis, both the primary and secondary data are used. 


\section{Weight Distribution Concepts:-}

The gross vehicle weight rating (GVWR) and the gross axle weight rating (GAWR) of each incomplete vehicle are specified on the cover of its incomplete vehicle document in conformance to the requirements of the federal motor vehicle safety regulations [8][9]. The final stage manufacturer is responsible to place the Gross Vehicle Weight Rating and the Gross Axle Weight Rating of each axle on the final vehicle certification label. The regulation states that the appropriate rating "shall not be less than the sum of the unloaded vehicle weight, rated cargo load, and 150 pounds times the vehicle's designated seating capacity" [8][9].

Unloaded vehicle weight means the weight of a vehicle with maximum capacity of all fluids necessary for operation of the vehicle, but without cargo or occupants.

During completion of this vehicle, Gross Vehicle Weight Rating and Gross Axle Weight Rating may be affected in various ways, including but not limited to the following:

a. The installation of a body or equipment that exceeds the rated capacities of this Incomplete Vehicle.

b. The addition of designated seating positions which exceeds the rated capacities of this incomplete vehicle.

c. Alterations or substitution of any components such as axles, springs, tires, wheels, frame, steering and brake systems that may affect the rated capacities of this incomplete vehicle.

The following formula is used to assure compliance with the regulations. Chassis curb weight and GVW rating is located below in each vehicle section. Always verify the results by weighing the completed vehicle on a certified scale.

Gross Vehicle Weight $($ GVW $)=$ Curb Weight of Chassis Weight of added body components, accessories or other permanently attached components + Total weight of passengers, and all load or cargo[8].

\section{Gross Axle Weight Rating:-}

The gross vehicle weight is further restricted by the gross axle weight rating (GAWR). The maximum GAWR for both front and rear axles is listed in each Vehicle Section. Weight distribution calculations must be performed to ensure Gross Axle Weight Rating is not exceeded. Always verify the results by weighing the completed vehicle on a certified scale.

Note: Although the front gross axle weight rating (FGAWR) plus the rear gross axle weight Rating (RGAWR) may exceed the gross vehicle weight rating (GVWR), the total GVW may not exceed the respective maximum Gross Vehicle Weight Rating.

The variation in the Gross Axle Weight Ratings allows the second stage manufacturer some flexibility in the design of the weight distribution of the attached unit [9].

\section{Weighing the Vehicle:-}

Front and rear Gross Axle Weight Ratings and total Gross Vehicle Weight Rating should be verified by weighing a completed loaded vehicle. Weigh the front and rear of the vehicle separately and combine the weights for the total Gross Vehicle Weight Rating [9]. All three weights must be less than the respective maximum shown in figure 1[8].

\section{Center of Gravity:-}

The design of the truck body should be such that the center of gravity of the added load does not exceed the guidelines as listed in each Vehicle Section. If the body is mounted in such a way that, the center of gravity height exceeds the maximum height of the center of gravity designated for each model, the directional stability at braking and roll stability at cornering will be adversely affected. A vertical and/or horizontal center of gravity calculation must be performed if a question in stability arises to ensure the designed maximum height of the center of gravity is not violated [9].

\section{Weight Distribution:-}

A truck as a commercial vehicle has but one purpose. That purpose is to haul some commodity from one place to another. A short distance or a long distance, the weight to be hauled, more than any other factor, determines the size of the truck. A small weight requires only a small truck; a large weight requires a large truck. A simple principle, but it can easily be misapplied. In any case, selecting the right size truck for the load to be hauled will ensure that the job 
will be done and that it will be able to be done with some degree of reliability and within the legal limitations of total gross weight and axle gross weights [9].

Not only must a truck be selected that will handle the total load, but the weight must also be properly distributed between the axles. This is of extreme importance from both a functional and economic aspect. If a truck consistently hauls less than its capacity, the owner is not realizing full return on his investment and his operating costs will be higher than they should be. If the truck is improperly loaded or overloaded, profits will be reduced due to increased maintenance costs and potential fines resulting from overloading beyond legal limitations.

Careful consideration must be given to distribution of the load weight in order to determine how much of the total, including chassis, cab, body and payload, will be carried on the front axle and how much will be carried on the rear axle, on the trailer axles and the total.

Moving a load a few inches forward or backward on the chassis can mean the difference between acceptable weight distribution for the truck or an application that will not do the job satisfactorily [8].

Every truck has a specific capacity and should be loaded so that the load distribution is kept within gross axle weight ratings and the truck's gross vehicle weight rating or gross combination weight rating (GCWR).

Improper weight distribution will cause problems in many areas like Excessive front end wear and failure, if center of payload is nearer to front end suspension, rapid tire wear when the weight on a tire exceeds its rating capacity, rough and erratic ride if the center of the payload is directly over or slightly behind the rear axle, the lack of sufficient weight on the front axle will create a bobbing effect, very rough ride, and erratic steering, hard steering when loads beyond the capacity of the front axle are imposed upon it, unsafe operating and conditions, high maintenance costs when a truck is overloaded, a dangerous situation may exist because minimum speeds cannot always be maintained, directional control may not be precise and insufficient braking capacity can cause longer than normal braking distance, Improper weight distribution and overloading cause excessive wear and premature failure of parts.

In this way, maximum payloads may be carried without exceeding legal limits. If the body is too long for a wheelbase, the center of the body and payload is placed directly over the rear axle. This places the entire payload on the rear axles, resulting in overloading the rear tires, rear axle springs and wheel bearings and potentially exceeding the rear axle legal weight limit. The front axle is then carrying no part of the payload and is easily lifted off the ground when going over rough terrain, creating a very rough ride and temporary loss of steering control. If the body is too short for the wheelbase used, frame stress may be increased and may result in excessive loads on the front axle. Excessive front axle loads increase wear on the kingpins and bushings, wheel bearings and steering gear. Excessive front axle loads also overstress the front axle, springs, tires and wheels. All of these contribute directly to higher maintenance costs and hard steering, both of which are undesirable. Weight distribution analysis involves the application of basic mathematical principles to determine the proper positioning of the payload and body weight in relation to the wheelbase of the truck chassis. It is much less expensive to work all of this out on paper, make mistakes on paper and correct them there than to set up the truck incorrectly and either have it fail to do the job or, much worse, fail completely. It is important to become familiar with the dimensions of the truck, as these will be needed to perform the necessary calculations [8] [9].

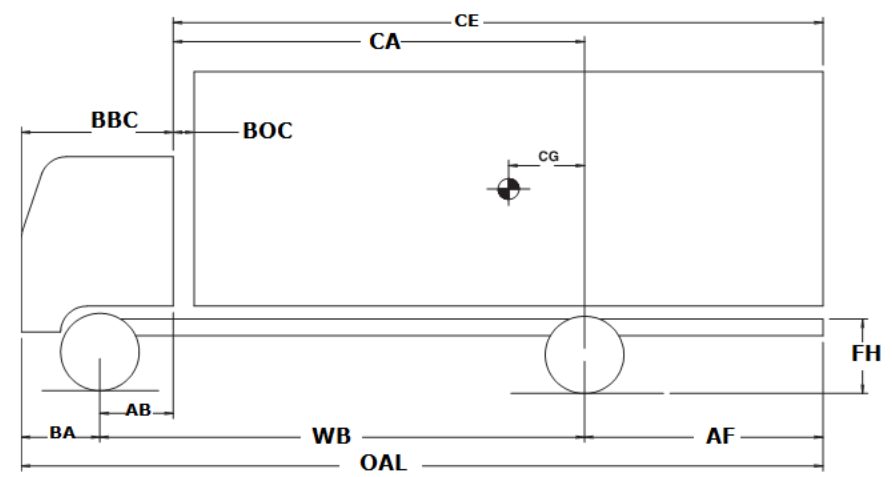

Figure 1 Weight distributions (Truck Isuzu NPR) 


\section{Glossary of Dimensions:-}

$B B C$ - Bumper to back of cab

$B A-$ Bumper to axle

WB - Wheelbase

$C A-$ Cab to axle

$A L-$ Overall length

$A B-$ Axle to back of $c a b$

$A F-$ Axle to end of frame

$B O C-$ Back of cab clearance

FH - Frame height

$C E-C a b$ to end of frame

\section{Weight Distribution Formula:-}

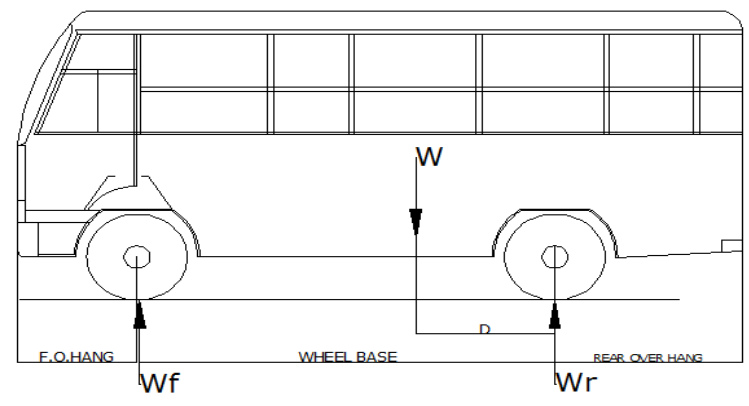

Figure 2 weight distribution of modified midi bus

$D$-Distance C.G. of body is ahead of rear axle

$\boldsymbol{F}$-Distance C.G. from point of C.G to front axle

$\boldsymbol{W B}$ - Wheelbase

$\boldsymbol{W}$ - Weight of body plus payload

$W_{f^{-}}$Portion of $W$ transferred to front axle

$W_{r^{-}}$- Portion of $W$ transferred to rear axle

\section{Basic Formulae:-}

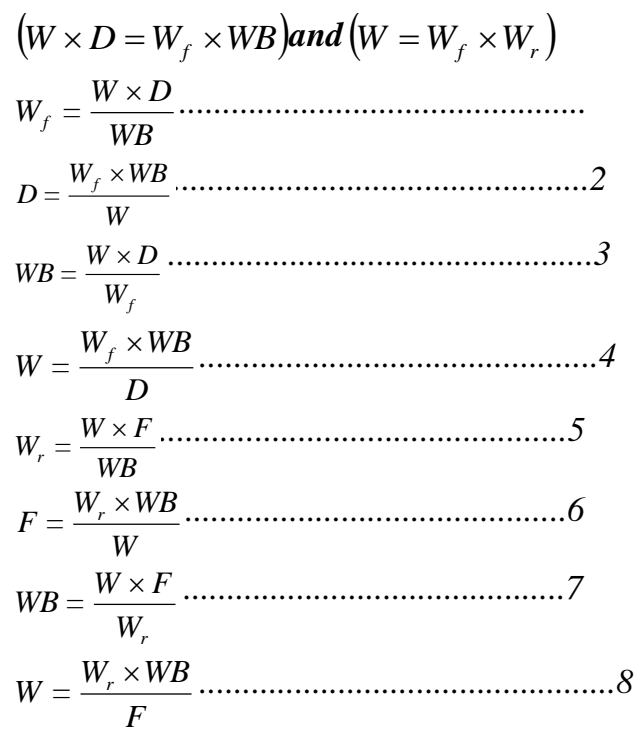




\section{Recommended Weight Distribution \% of Gross Vehicle Weight Conventional 2 Axles:-}

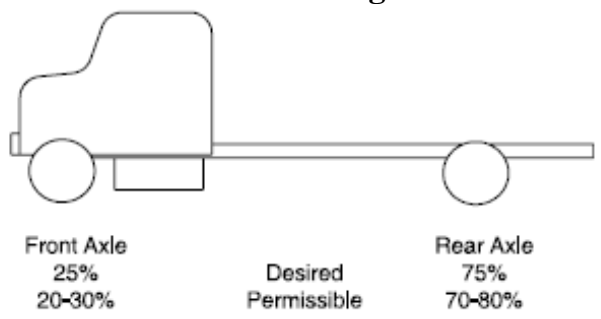

Figure 3 weight distribution \% of gross vehicle weight by axle (Isuzu motors)

\section{Calculation of Center of Gravity:-}

In this case we have the following data to calculate the center of gravity of Isuzu NPR series

Note: The body manufacturer can provide the body length and weight, or actual measurements of the body may be taken with a tape [5].

The following Table 1 compares the dimensions of original truck to the modified bus.

Table 1 Comparisons of the truck and the bus

\begin{tabular}{|l|l|l|l|}
\hline No & Dimensions & Isuzu NPR 66L & Modified NPR 66L midi bus \\
\hline 1 & Model name & NPR 66L & NPR 66L \\
\hline 2 & WB mm & 3365 & 3365 \\
\hline 3 & FOH mm & 1085 & 1100 \\
\hline 4 & ROH mm & 1505 & 2300 \\
\hline 5 & OAL mm & 5995 & 6765 \\
\hline 6 & GVW kg & $6300 \mathrm{~kg}$ & $>6300 \mathrm{~kg}$ \\
\hline 7 & Windshield & Laminated uniform and curved & Not curved \& two pieces \\
\hline
\end{tabular}

Center of Gravity for Chassis-Cab Mass:-

Weight on Front Axle, $\mathrm{W}_{\mathrm{f}}=1535 \mathrm{~kg}$

Weight on Rear Axle, $\mathrm{W}_{\mathrm{r}}=775 \mathrm{~kg}$

Total weight, $\mathrm{W}=2310 \mathrm{~kg}$

Center of gravity, $\mathrm{D}=$ ?

$$
\begin{aligned}
& D=\frac{W_{f} \times W B}{W} \\
& D=\frac{1535 \mathrm{~kg} \times 3.365 \mathrm{~m}}{2310 \mathrm{~kg}}=\mathbf{2 . 2 3 6} \mathbf{m}
\end{aligned}
$$

Therefore, the center of gravity, D of the chassis-cab mass is 2.236 meters ahead of rear axle.

\section{Center of Gravity of Truck:-}

The following original equipment manufacturer (OEM) dimensions should be considered before calculating the center of gravity. These are:

Table 2 Original Equipment Manufacturer specification

\begin{tabular}{|l|l|}
\hline Wheel base (WB) & $3365 \mathrm{~mm}$ \\
\hline Front Overhang (FOH) & $1085 \mathrm{~mm}$ \\
\hline Rear Overhang (ROH) & $1505 \mathrm{~mm}$ \\
\hline Overall length (OAL) & $5995 \mathrm{~mm}$ \\
\hline Gross Vehicle Weight & $6300 \mathrm{~kg}$ \\
\hline Desired weight on front axle & $25 \%$ of GVW \\
\hline Desired weight on rear axle & $75 \%$ of GVW \\
\hline
\end{tabular}

Source: Isuzu NPR 66/66-2 manual 2007 
Desired \% of weight on front axle is $25 \%$ of $W$

$W_{f}=0.256 \times 6300 \mathrm{~kg}=1575 \mathrm{~kg}$

Desired \% of weight on rear axle is $75 \%$ of $W$

$W_{r}=0.75 \times 6300 \mathrm{~kg}=4725 \mathrm{~kg}$

Gross Vehicle Weight, $W=6300 \mathrm{~kg}$

Then center of gravity, $\mathrm{D}$ is equal to

$$
D=\frac{1575 \mathrm{~kg} \times 3.365 \mathrm{~m}}{6300 \mathrm{~kg}}=\mathbf{0 . 8 4 m}
$$

Table 3 Dimensional deviations during modification

\begin{tabular}{|l|l|l|}
\hline \multicolumn{2}{|c|}{ Original truck } & Modified bus \\
\hline Wheel base (WB) & $3365 \mathrm{~mm}$ & $3365 \mathrm{~mm}$ \\
\hline Front Overhang (FOH) & $1085 \mathrm{~mm}$ & $1100 \mathrm{~mm}$ \\
\hline Rear Overhang (ROH) & $1505 \mathrm{~mm}$ & $2300 \mathrm{~mm}$ \\
\hline Overall length (OAL) & $5995 \mathrm{~mm}$ & 6765 \\
\hline Gross Vehicle Weight (GVW) & $6300 \mathrm{~kg}$ & $>6300 \mathrm{~kg}$ e.g.8140kg \\
\hline Desired weight on front axle & $25 \%$ of GVW & \\
\hline Desired weight on rear axle & $75 \%$ of GVW & \\
\hline
\end{tabular}

\section{Center of Gravity of Bus with Full Passengers:-}

Tare weight $=5440 \mathrm{~kg}$, considering the severe case from the table 1

Payload of passengers 25 passengers +1 driver +1 co-driver $=27$

Payload $=27 \times 100 \mathrm{~kg}$ per passengers $=\mathbf{2 7 0 0} \mathbf{~ k g}$

Gross Vehicle Weight $(\mathrm{GVW})=$ Payload + Tare weight of Bus

$\mathrm{GVW}=2700 \mathrm{~kg}+5440 \mathrm{~kg}=\mathbf{8 1 4 0} \mathbf{~ k g}$

During bus bodies building the following dimensions are modified.

$$
\begin{aligned}
& \mathrm{W}_{\mathrm{f}}=0.25 \times 8140=2035 \mathrm{~kg} \\
& \mathrm{~W}_{\mathrm{r}}=0.75 \times 8140=6105 \mathrm{~kg}
\end{aligned}
$$

Thus, $D=\frac{2035 \times 3.365}{8140}=0.84 \mathrm{~m}$ ahead of the rear axle

During body construction, the rear over hang was increased by lengthening the chassis by welding. This further shifts the center of gravity to move very close to the rear axle.

If the body is too long for a wheelbase, the center of the body and payload is placed directly over the rear axle. This places the entire payload on the rear axles, resulting in overloading the rear tires, rear axle springs and wheel bearings and potentially exceeding the rear axle legal weight limit (Isuzu motors limited 2007).

Moving a load a few inches forward or backward on the chassis can mean the difference between acceptable weight distribution for the truck or an application that will not do the job satisfactorily (2007 Series, Chevrolet and GMC NSeries Isuzu GM USA).

When there is the possibility that axle loads will exceed existing weight laws and regulations, careful weight distribution is necessary to provide a correct balance between front and rear axle loads and total load within legal limitations. 


\section{Rear Overhang Limit:-}

Rear over hang must not exceed the $60 \%$ of the wheelbase [10].Thus the sample measurement of bus rear overhang is $2300 \mathrm{~mm}$ which is larger than $60 \%$ of wheelbase $(3365 \mathrm{~mm})$. This shows that the weight distribution on the rear wheels extremely larger than the recommendations of the manufacturer.

\section{Weight Deviation from Specification:-}

Tare weight of the 150 modified buses registered by transport authority (TA) from the years 2010 to 2012 collected. The weight dada of buses randomly selected are 150 buses in the three years of which 50 midi buses in each year. The Ethiopian Transport Authority, allows the passengers to have a right to use the bus with the 25 kilograms of luggage and the passenger average weight is 75 kilograms [11].

These are summarized as follows:

- Tare weight of a bus after modification $\leq 3800 \mathrm{~kg}$

- Weight one passenger $=75 \mathrm{Kg}+25 \mathrm{~kg}=100 \mathrm{~kg}$.

As the performed investigation, the tare weight of locally manufactured bus bodies from the years 2010-2012 was $4197.4 \mathrm{~kg}, 4177.4 \mathrm{~kg}$, and $4197.4 \mathrm{~kg}$ respectively, which is much greater than the allowed maximum tare weight limit which is $\leq 3800 \mathrm{~kg}$.

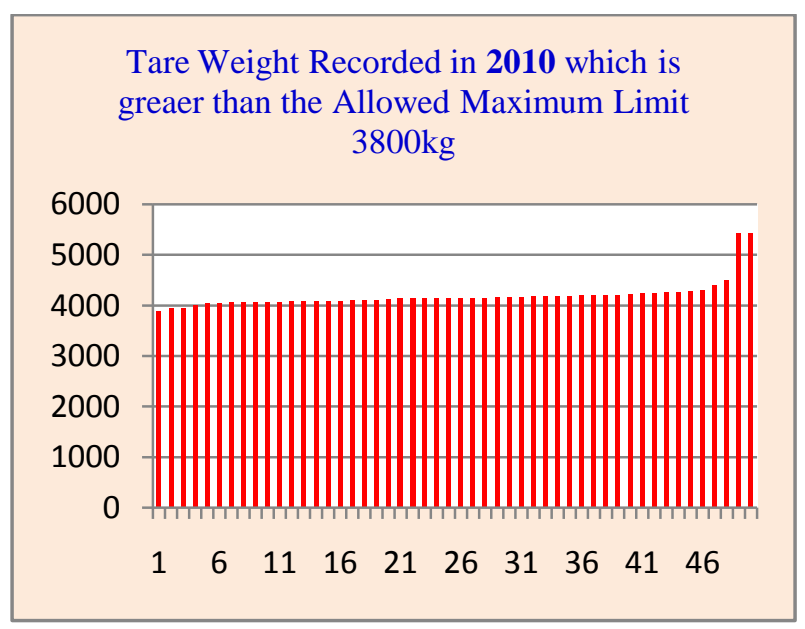

Figure 4(a)Tare weight in the year 2010

Tare Weight recorded in 2011 which is greater than the allowed maximum limit $3800 \mathrm{~kg}$

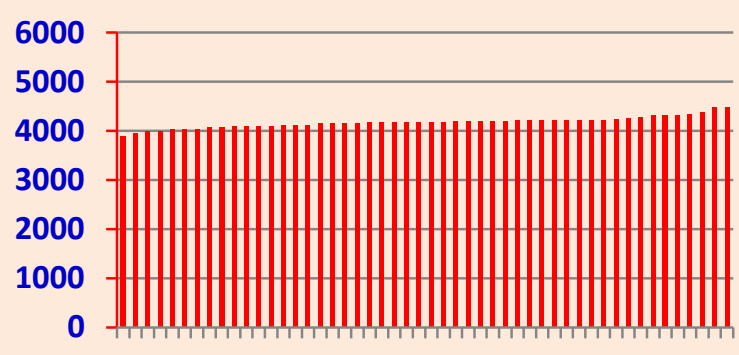

$\begin{array}{llllllllll}1 & 6 & 11 & 16 & 21 & 26 & 31 & 36 & 41 & 46\end{array}$

Figure 4(b)Tare weight in the year 2011 


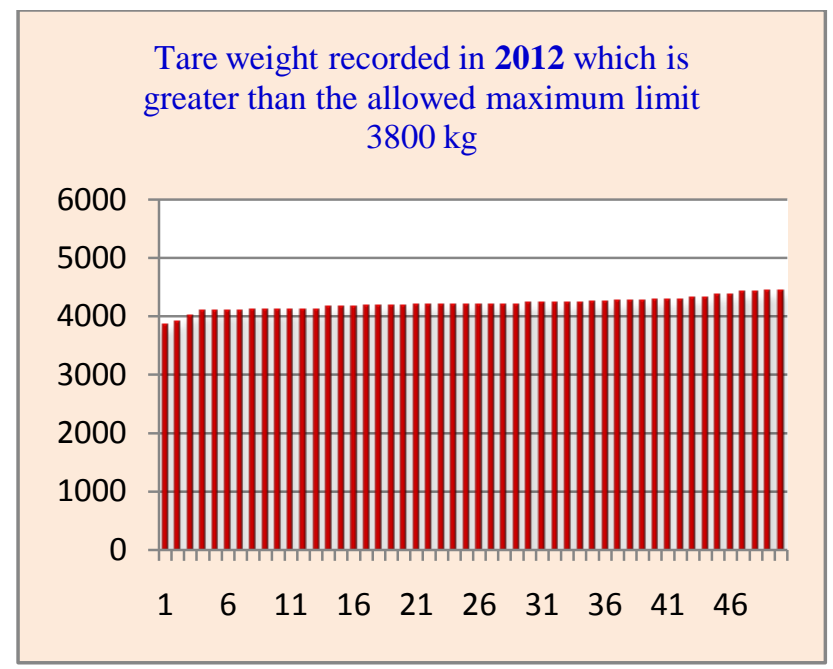

Figure 4(c) Tare weight in the year 2012

Figure 4(a), (b) and (c) the graphs show that TW is $>3800 \mathrm{~kg}$

The average of the tare weight 2010-2012 from the arbitrarily selected sample size of 150 midi buses, the average of each year is $4197.4,4177.4$, and $4197.4 \mathrm{~kg}$ respectively. The average of the three years is greater than the specified range of weight.

\section{Reasons for the Overweight of Modified Buses:-}

Absence of Code of Practices for Bus body building design and Approval:-

The mandatory requirements for buses are intended to bring together the Standards, procedures, specifications and transport regulations for the purpose of regulating and determining the rules for the manufacture, construction and registration of a bus in the country.

The Transport authority should examine and check the mandatory requirements and periodically amend them in accordance with the safety, engineering and ecological standardization. An important part in consolidating the mandatory requirements is based on many years of testing, manufacturing and operating buses in the country, findings of road accident investigations etc., whose purpose is to lead to raising the level of comfort and safety for the passenger and road transport.

In view of this, committees of experts should be convened, to represent various bodies dealing with buses, which include representatives of the Vehicles Department in the Ministry of Transport, representatives of local bus manufacturers, public transport cooperatives and bus importers. The purpose of preparing code of practice leads to improvement of the structure of a bus, passenger safety and comfort, technological progress, the bus owners and insurance companies due to reduced cost of maintenance, reduced property and life loss.

So the following table 4 shows the weight of the problem in the industry from highest contributor to the least contributor depending on the feedback collected from different groups of people concerned in the sector like supervisors, transport officials, technicians, body builders, and passengers. According to the respondents $46 \%$ said the main problem is absence of national standard or code for bus body building and no continuous follow up the builders.

Table 4 Major reasons for defects in bus body building

\begin{tabular}{|l|l|l|}
\hline N0 & \multicolumn{1}{|c|}{ Category } & $100 \%$ \\
\hline 1 & No National Standard & 46 \\
\hline 2 & No well Organized Bus Body design & 36 \\
\hline 3 & Shortage/No Advanced Machines & 8 \\
\hline 4 & Poor material selection & 6 \\
\hline 5 & Operators Skill & 3 \\
\hline 6 & Poor/ No Workshops & 2 \\
\hline
\end{tabular}




\section{Cause Analysis Tools:-}

Pareto Charts Analysis:

The main problems shown in table 4 are analyzed according to Pareto chart below.

A Pareto chart is a bar graph. The lengths of the bars represent frequency or cost (time or money), and are arranged with longest bars on the left and the shortest to the right. In this way the chart visually depicts which cause is more significant [12] [13].

It is used when analyzing data about the frequency of problems or causes in a process and when there are many problems or causes and you want to focus on the most significant.

Thus, the Pareto chart shows the greatest solution can be obtained or the problem of the bus body building can be solved by preparing the national standard for all bus body building industries and continuous follow up, and checks during and after modification.

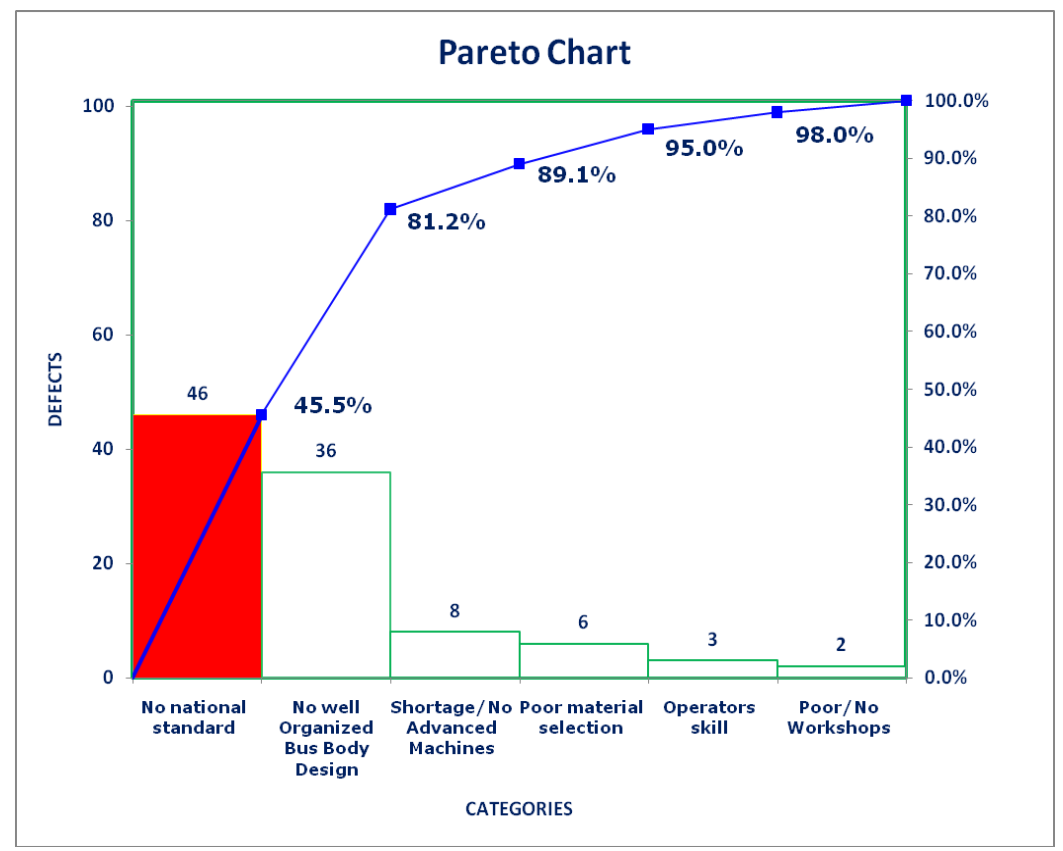

Figure 5Pareto chart analysis for the most significant Causes of the problems.

If the bus body building code is prepared with appropriate scientific rules and regulation and continuous check-up followed, the existing problems are reduced by $45.5 \%$ as indicated in chart shown in figure 5 [12].

If the problems related with bus body builders are obtained solution, the problems are further reduced by $81.2 \%$ and finally solving problems related to bus owners we can achieve better results [13].

\section{Cause-and-Effect Diagram Analysis}

The Cause and Effect diagram also known as the "fishbone" or "Ishikawa" diagram after its creator Kaoru Ishikawa is used to systematically list all the different causes that can be attributed to a specific problem (or effect). A cause-andeffect diagram can help identify the reasons why a process goes out of control or it is a common tool used for a cause and effect analysis, where you try to identify possible causes for a certain problem or event [14].

The cause and effect diagrams give a fast and comprehensive overview of how a single quantity depends on other quantities. Common categories in a Fishbone Diagram are: Machine (equipment), method, manpower, material, environment, Management (policies), maintenance [14].

The chart in figure 6 identifies multiple potential causes for the problem at hand. The "bones" of the normal potential "cause" categories include people, methods, machinery, and materials. As problem situations vary, this tool has the added benefit of being able to creatively identify different elements to better fit the individual situation. 


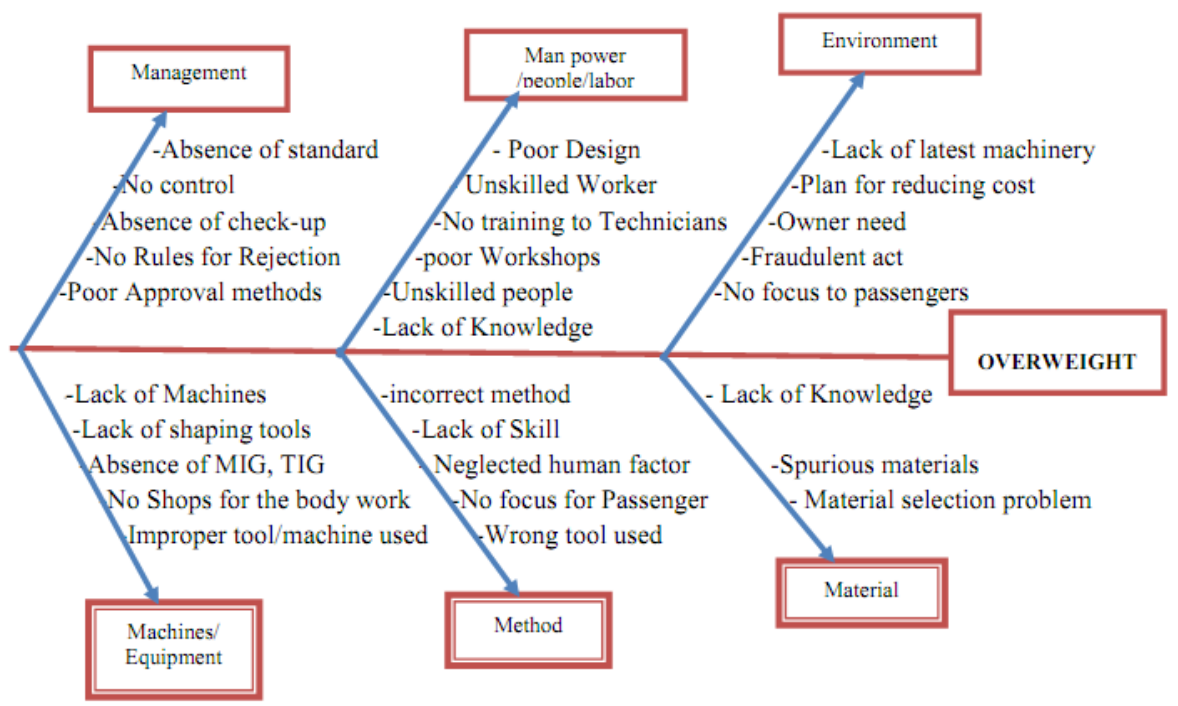

Figure 6 Fishbone or Cause-and-effect diagram

\section{Comparison of the Structures of Body Frame Work:-}

Mounting Frame as Floor assembly: A mounting frame with continuous longitudinal members is not required if the body floor assembly can assume the mounting frame function. The longitudinal members can also be integrated in the body. If the mounting frame longitudinal members are intersected by the chassis members, the connection between the longitudinal and cross members must be rigid and resistant to torsion and bending.

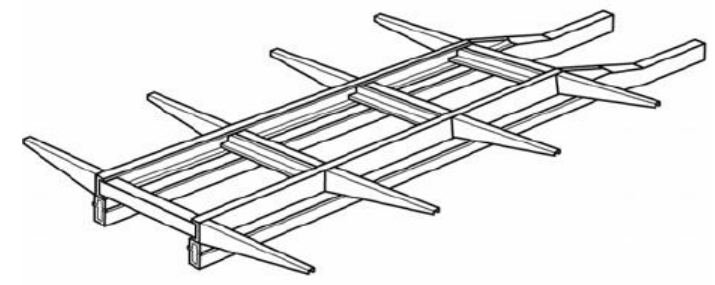

Figure 7 Longitudinal members are intersected by the chassis members to resist torsion \& bending (sprinter, 2007)

The floor assembly of locally built buses is greatly different from the shown in figure 8 .

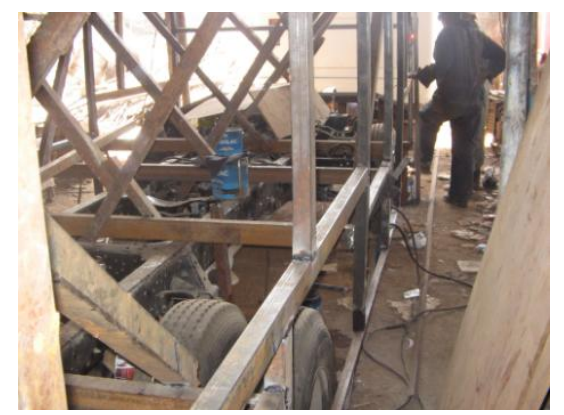

Figure 8 Floor assembly of locally modified midi bus (Source: field survey)

\section{Self-Supporting Bodies}

A mounting frame with continuous longitudinal members is not required if the body floor assembly must have the same mounting frame function.

Self- supporting bodies must have the same characteristics as specified mounting frame. The body floor assembly must have the same rigidity and moment of resistance as a mounting frame. 


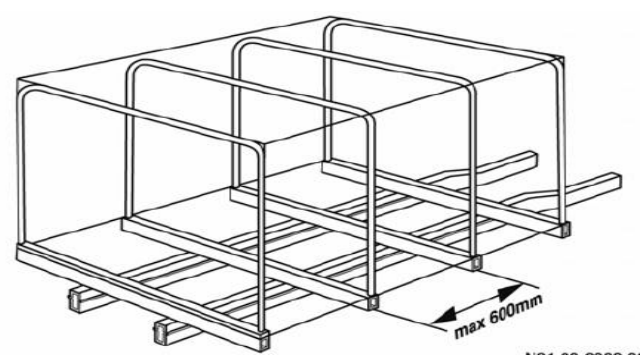

Figure 9Body design spacing maximum 600mm

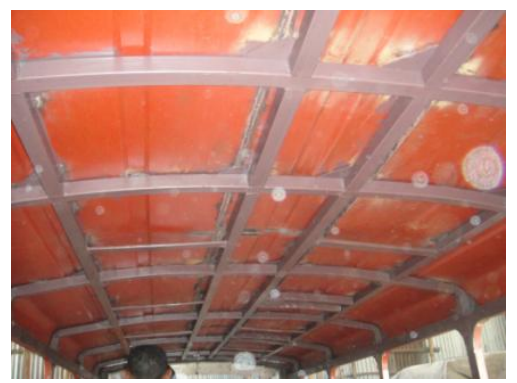

Figure 10 Roof structure of locally made (field photo)

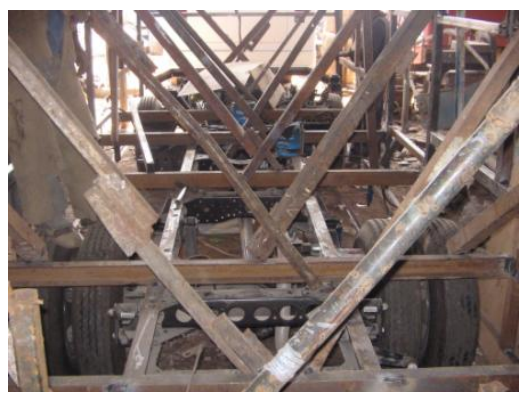

Figure 11Framework of locally Made (Field photo)

The safest roof structures are shown in the figure 12. These body structures are very strong, stiff and provide more safety and comfort to the bus occupants (sprinter 2007). The roof structure must be tested for strength and stiffness, to reduce the life fatalities during the bus roll-over accidents.

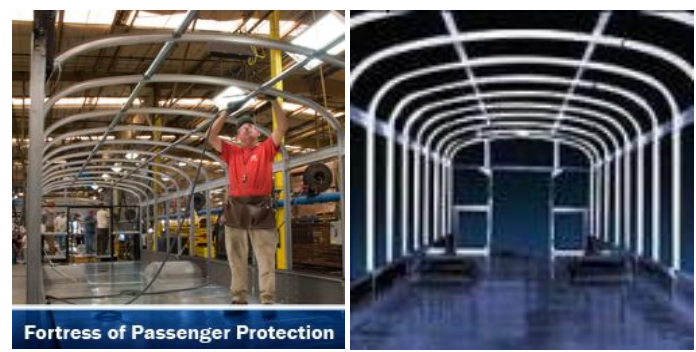

Figure 12Best framework of body design (Sprinter, Dec, 2007)

Comparing figures 7,9 , and 12 , with locally built bus bodies shown in figures 8,10 , and 11 the following summary concludes:

Locally built buses should follow the following important guides to obtain strong structures to resist torsion and bending loads and to guarantee passengers safety. 
- The pillars should be round hollow sections extending from the right side chassis to roof structure and then to the left chassis without welding to get self-supporting bodies and have the same rigidity. The stress is uniformly distributed among the structures.

- In locally modified buses the pillars or posts are rectangular hollow sections (RHS) which are cut into pieces each of 2 meters long. These structure minimum welded in four places to make side and roof structures. The welded surface stress distribution is concentrated on the welded section.

\section{Mandatory Tests on the bus:-}

From the values of the measurements taken it is obvious that the measurements are deviated from the given standard values of the minimum requirements.

To conclude the above all analysis result the following photograph is a strong witness for little or no consideration of passengers' safety and comfort, poor material joining and assembling techniques.

The other most important idea is the body must be tested to the following to measure the stiffness and strength to increase the safety for the bus occupants. Figure 13shows the vehicle body structure conditions during rollover accident. The bus structures completely disintegrated and passengers are thrown out the bus interior, which results in increase in life fatalities instead of minimizing risks [15][16].

Each bus should be tested for the following tests in order to ensure stiff and strong structures should be used to ensure to provide reliable safety, comfort and durable structure for the bus owners and passengers [12][16].

a. Vehicle Roll over test: While the vehicle need not be in a fully finished condition, it shall be representative of production vehicles in respect of the mass of the vehicle in running order, center of gravity and distribution of mass as declared by the manufacturer.

b. Joint Strength Test: Each body panel joint shall be capable of holding the body panel to the member to which it is joined when subjected to a force of $60 \%$ of the tensile strength of the weakest joined body panel.

c. Vehicle Stability Test: The stability of a vehicle shall be considered to comply with the requirement if the angle at which overturning occurs is greater than 28 degrees from the horizontal (acceptance criteria).

d. Impact Strength for Bumpers: the front and rear bumpers of the vehicle shall meet the requirements prescribed in relevant standard as and when notified.

e. Water Test: every vehicle must be tested for water or rain test to prevent the entry of rain or leakage to the bus interior [12] [16] [17].

f. Roof Strength Test: should be performed to reduce fatalities during vehicle rollover accident.

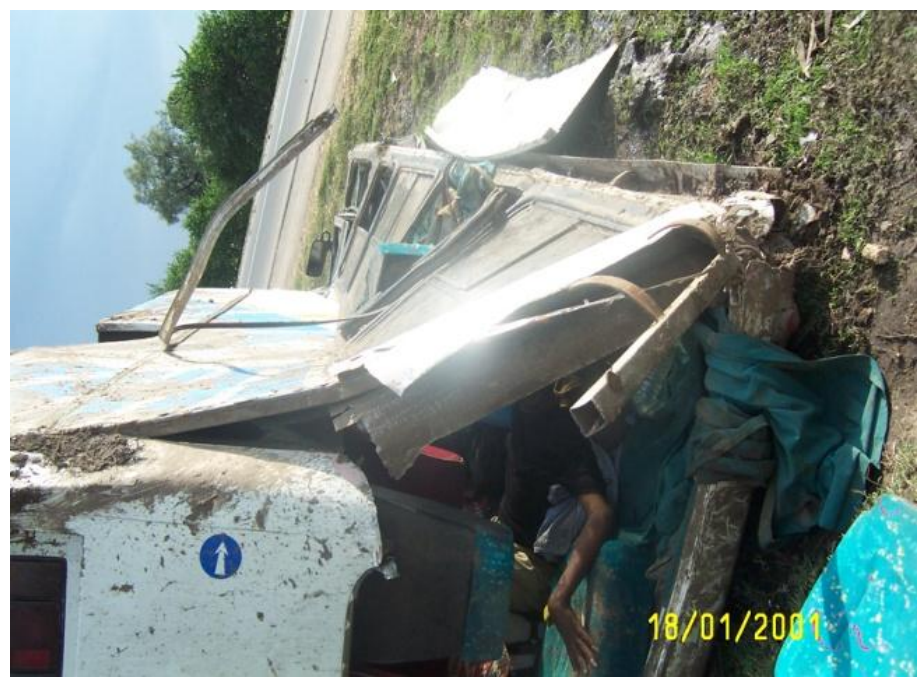

Figure 13 Rolled over bus and body structures response during accident (source: field photo) 


\section{Conclusions:-}

Absence of proper national standard/code of practice for bus body building design and approval to regulate and control the builders allowed the builder to follow their own experience. Thus, setting and implementing the rules for the body builders corrects the existing challenges and helps to manufacture quality products which are economical, safe and comfortable. In addition, proper design which includes complete technical specifications, general drawings of bus structure along with complete dimensions, its components, seats, interior/ exterior fittings, electrical systems, wiring harness, photometric items and other accessories along with complete details of materials used, their specification, manufacturing tolerances shall be provided.

The vehicle performance parameters like; the power, speed and fuel consumption greatly affected by the overweight. Using lightest material like High Strength Steel (HSS), Acrylonitrile Butadiene Styrene (ABS), Polyvinyl-Chloride (ABS-PVC), Composite Body Solutions (CBS), Fiber Reinforced Plastics (FRP), mineral wood the weight can be reduced. Plastics have gained wide usage as transit vehicle liners because highly suitable components can be economically produced, usually at reduced weight [18].

\section{References:-}

1. SPRINTER, Body Builder Information Book, December 11, 2007 Washington, USA

2. Automotive Engineering International, SAE International, Sept. 2003, Mar\& Aug. 2004)

3. Geoff Davies, Materials for Automotive Bodies, Elsevier, 2003, Ltd, UK

4. Automotive Engineer-The Magazine for the Industry, March 2001

5. Robert Bosch, Automotive Handbook, $3^{\text {rd }}$ edition 1993.

6. D. Gordon, David L. Greene, Marc H. Ross, Tom P. Wenzel, Improving Vehicle Safety and Fuel Economy through Improvements in vehicle Design and Materials, experts workshop,2007, University of Michigan

7. https://www.ipcc.ch/publications_and_data/ar4/wg3/en/ch5s5-3-1-1.html

8. 2007 W-Series (Chevrolet \& GMC) N-Series (Isuzu), General Motors Isuzu Commercial Truck, LLC (GMICT) and American Isuzu Motors Inc

9. Isuzu Truck, Weight Distribution Concepts, Weight Restrictions, 2016

10. Vehicle standards information sheet No 5 Sydney/www.vicroads.vic.gov,au April 2007

11. Fright vehicle to passenger bus modification rules, technical and vehicle purchasing

12. http://www.asg.org

13. http://asq.org/learn-about-quality/cause-analysis-tools/overview/pareto.html

14. http://asq.org/learn-about-quality/cause-analysis-tools/overview/fishbone.html

15. Directive of the European Parliament and of the Council Journal, Nonember.2002.

16. Code of Practice for Bus Body Design and Approval, $1^{\text {st }}$ Ed, Aug 2008, Delhi, India

17. Mandatory Requirements for Buses, $6^{\text {th }}$ edition, June 2003, Tel Aviv, Israel

18. Jason C. Brown, A. John Robertson, Stan T. Serpento, Motor Vehicle Structures Concepts and Fundamentals, 2004, Butterworth Heinemann, UK

19. Pawlowski. J. Vehicle Body Engineering, 1969, Business Books Ltd.UK

20. Isuzu Motors Limited Tokyo, Japan http://www.isuzu.co.jp) 